\title{
Interlaboratory studies on in vitro test methods for estimating in vivo resorption of calcium phosphate ceramics
}

\author{
Atsuo Ito ${ }^{\mathrm{a}^{*}}$, Yu Sogo ${ }^{\mathrm{a}}$, Atsushi Yamazaki ${ }^{\mathrm{b}}$, Mamoru Aizawa ${ }^{\mathrm{c}}$, \\ Akiyoshi Osaka ${ }^{\mathrm{d}}$, Satoshi Hayakawa ${ }^{\mathrm{d}}$, Masanori Kikuchi ${ }^{\mathrm{e}}$, \\ Kimihiro Yamashita ${ }^{\mathrm{f}}$, Yumi Tanaka ${ }^{\mathrm{f} 1}$, Mika Tadokoro ${ }^{\mathrm{g}}$, Lídia Ágata de Sena ${ }^{\mathrm{h}}$, \\ Fraser Buchanan ${ }^{\mathrm{i}}$, Hajime Ohgushi ${ }^{\mathrm{g}}$, and Marc Bohner ${ }^{\mathrm{j}}$
}

${ }^{a}$ National Institute of Advanced Industrial Science and Technology (AIST), Tsukuba, Ibaraki 305-8566, Japan

${ }^{\mathrm{b}}$ Department of Resources and Environmental Engineering, Waseda University, Shinjuku-ku, Tokyo 169-8555, Japan

${ }^{c}$ Department of Applied Chemistry, School of Science and Technology, Meiji Univ., Tama-ku, Kawasaki, Kanagawa 214-8571, Japan

${ }^{\mathrm{d}}$ Department of Medical and Bioengineering Science, Graduate School of Natural Science and Technology, Okayama University, Tsushima, Okayama, Okayama 700-8530, Japan

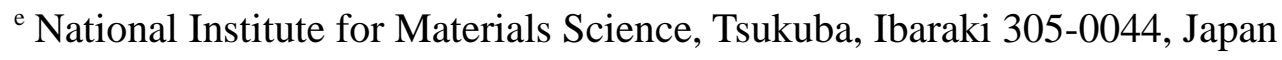

${ }^{\mathrm{f}}$ Institute of Biomaterials and Bioengineering, Tokyo Medical and Dental University, Chiyoda-ku, Tokyo 101-0062, Japan

${ }^{g}$ National Institute of Advanced Industrial Science and Technology (AIST), Amagasaki, Hyogo 661-0974, Japan

${ }^{\mathrm{h}}$ Instituto Nacional de Metrologia, Qualidade e Tecnologia - Inmetro 
Diretoria de Metrologia Científica e Industrial - Dimci

Divisão de Metrologia de Materiais - Dimat

CEP 25250-020 Xerém - Duque de Caxias - RJ, Brazil

i Queen's University, School of Mechanical and Aerospace Engineering, Ashby Building, Stranmillis Road, Belfast, BT9 5AH, UK

${ }^{\mathrm{j}}$ RMS Foundation, Bischmattstr. 12,

CH-2544 Bettlach, Switzerland

${ }^{1}$ Present address: Department of Industrial Chemistry, Faculty of Engineering, Tokyo University of Science, Shinjuku-ku, Tokyo 162-0826, Japan

* Corresponding author. Tel.: +81 29861 2557; fax +81 298616149.

E-mail address: atsuo-ito@aist.go.jp

This study was carried out as Project 5 of Technical Working Area (TWA) 30, Versailles Project on Advanced Materials and Standards (VAMAS). Data obtained using Specimens 3, 4, 7, 8, 9 and 12 (Table 1) measured under conditions A-3, A-4, A-6, B, C, D, E-1, E-2, and F (Table 2) are used in JIS T 0330-3:2012. These data and related materials are reproduced with permission. 


\begin{abstract}
A potential standard method for measuring the relative dissolution rate to estimate the resorbability of calcium-phosphate-based ceramics is proposed. Tricalcium phosphate (TCP), magnesium-substituted TCP (MgTCP) and zinc-substituted TCP (ZnTCP) were dissolved in a buffer solution free of calcium and phosphate ions at $\mathrm{pH} 4.0,5.5$ or 7.3 at nine research centers. Relative values of the initial dissolution rate (relative dissolution rates) were in good agreement among the centers. The relative dissolution rate coincided with the relative volume of resorption pits of ZnTCP in vitro. The relative dissolution rate coincided with the relative resorbed volume in vivo in the case of comparison between microporous MgTCPs with different Mg contents and similar porosity. However, the relative dissolution rate was in poor agreement with the relative resorbed volume in vivo in the case of comparison between microporous TCP and MgTCP due to the superimposition of the Mg-mediated decrease in TCP solubility on the Mg-mediated increase in the amount of resorption. An unambiguous conclusion could not be made as to whether the relative dissolution rate is predictive of the relative resorbed volume in vivo in the case of comparison between TCPs with different porosity. The relative dissolution rate may be useful for predicting the relative amount of resorption for calcium-phosphate-based ceramics having different solubility under the condition that the differences in the materials compared have little impact on the resorption process such as the number and activity of resorbing cells.
\end{abstract}

\title{
Keywords
}

Dissolution; calcium phosphate; resorption; round-robin test 


\section{Introduction}

The evaluation and subsequent optimization of the resorbability of calcium phosphate are crucial in the use of resorbable calcium phosphates. Resorbable calcium phosphates include $\beta$-tricalcium phosphate ( $\beta$-TCP), $\alpha$-tricalcium phosphate, carbonated hydroxyapatite, low-crystalline hydroxyapatite, and a certain range of biphasic hydroxyapatite and $\beta$-TCP. These calcium phosphates are not only osteoconductive but are also gradually resorbed in a long period of time after implantation [1-10]. The rate of resorption needs to be optimized depending on the intended purpose and be balanced with bone tissue regeneration for successful clinical treatments. Moreover, recent findings suggest that the optimized resorption or degradation of calcium phosphates itself can enhance bone tissue regeneration through an immunomodulatory action [11-14].

Possible alternatives to animal testing for evaluating the resorbability include cell-based assay, simulation and dissolution tests. Cell-based resorption assay uses a variety of resorbing cells including primary and tumor osteoclasts, differentiated osteoclasts and monocyte/macrophage cell lines [15, 16]. A limitation of cell-based assay is that the assay requires a flat surface for evaluating resorption lacunae or pits. Thus, it is difficult to evaluate the resorbability of porous bodies and granules. Simulation is an alternative to animal testing that is applicable to porous bodies. Recent simulations have demonstrated an excellent correlation with in vivo resorption data for macroporous $\beta$-TCP $[17,18]$. The simulation is intrinsically based on the paradigm that only osteoclasts and/or macrophages in the vicinity of blood vessels can survive and resorb the surface of the pores. A dissolution test is potentially a chemical alternative to animal testing for the evaluation of resorption because the resorption of calcium 
phosphate is substantially a process of cell-mediated dissolution in acidic fluids inside the resorption lacunae underneath osteoclasts or in the phagolysosome of phagocytic cells. The pH values of the acidic fluids have been reported to be 3.9-6.0 [19-23].

Different dissolution tests of calcium phosphates have been carried out under various conditions using either continuous or discontinuous measurement techniques. The continuous measurement techniques include the constant composition method [24-26], the constant $\mathrm{pH}$ method [27] and other methods using electrodes [28]. The discontinuous measurement techniques include pharmacopoeia methods such as the BP (British Pharmacopoeia) and USP (United States Pharmacopeia) methods and other intermittent sampling-and-analysis methods [29, 30]. The $\mathrm{pH}$ values ranged from $\approx 3$ to 7.4 in these dissolution tests. The dissolution tests did not necessarily aim to predict in vivo resorption. However, some dissolution tests of calcium phosphates have been found to be predictive of their resorption behavior in vivo [31].

On the basis of the background described above, a dissolution test method to predict the resorption of calcium phosphates is proposed as a potential standard method in the present study. The efficacy and limitations of the method were evaluated by round-robin tests as well as comparison with in vitro and in vivo resorption studies.

\section{Materials and methods}

\subsection{Materials}

Specimens of sintered polycrystalline TCP, magnesium-containing TCP (MgTCP) and zinc-containing TCP (ZnTCP) were used (Table 1). TCP25 and TCP35 denote 100\% macroporous bodies of TCP with intended relative densities of 25\% and 35\%, 
intended relative densities of 60, 70 and 90\%, respectively. 1.0MgTCP, 1.7MgTCP and 3.4MgTCP denote 100\% microporous bodies of MgTCP containing 1.0, 1.7 and 3.4 mol\% of Mg, respectively, with an intended relative density of $60 \% .0 .5 \mathrm{ZnTCP}$ and 1.0ZnTCP denote $100 \%$ microporous bodies of ZnTCP containing 0.5 and $1.0 \mathrm{~mol} \%$ of Zn, respectively, with an intended relative density of 90\%. Scanning electron microscopy (SEM) images of the specimens are shown in the supporting data (Fig. S1). The specimens have block, cylinder and disk shapes with dimensions as listed in Table 1. TCP25 and TCP35 had a block shape and were used in the dissolution study. TCP60, TCP70, 1.0MgTCP, 1.7MgTCP and 3.4MgTCP had a cylinder shape and were used in the dissolution and in vivo resorption studies. TCP90, 0.5ZnTCP and 1.0ZnTCP had a disk shape and were used in the dissolution and osteoclastic resorption studies. The cylinder specimens used for the in vivo resorption study had 1-mm-thick biphasic (TCP and hydroxyapatite) portions with a $\mathrm{Ca} / \mathrm{P}$ molar ratio of 1.60 at both ends. The biphasic portion was microscopically non-resorbable in the present animal model (Fig. S2). The biphasic portion was used to define the base line of zero resorption when measuring the resorbed volume in the in vivo study. All specimens were prepared by sintering in the temperature range from 1030 to $1100{ }^{\circ} \mathrm{C}$ depending on the chemistry and intended relative density. All the specimens except for the macroporous TCP25 and TCP35 were prepared in the research center A. The macroporous specimens were prepared by Covalent Materials Co., Japan, then subjected to quality inspection at research center A.

\subsection{Interlaboratory dissolution tests}

Interlaboratory dissolution tests were performed at nine research centers (A-I; Table 2). The protocol for the dissolution tests is described in the supporting data. Briefly, the 
specimens were dissolved in either $0.05 \mathrm{M}$ potassium hydrogen phthalate buffer solution at $\mathrm{pH} 4.0,0.08 \mathrm{M}$ acetic acid-sodium acetate buffer solution at $\mathrm{pH} 5.5$ or 0.05 M Tris-HCl buffer solution at pH 7.3 while stirring the buffer solutions. The dissolution temperature was $25{ }^{\circ} \mathrm{C}$ except in the pharmacopoeia method, where it was $37{ }^{\circ} \mathrm{C}$ (A-5 in Table 2). The dissolution period was 5, 18, 30, 180 or $300 \mathrm{~min}$, where $30 \mathrm{~min}$ was adopted in most cases. The volumes of the solutions were from 35 to $100 \mathrm{~mL}$ except in the pharmacopoeia method, where it was $200 \mathrm{~mL}$. The calcium concentration was measured continuously or intermittently. The continuous measurement was made using calcium-ion-selective electrodes. The intermittent measurement was made by collecting $1 \mathrm{~mL}$ of solution at intervals of 3 or 5 min except in the pharmacopoeia method, in which $5 \mathrm{~mL}$ was collected at intervals of $60 \mathrm{~min}$. The collected solution was analyzed for calcium using atomic absorption spectroscopy (AAS), inductively coupled plasma atomic emission spectrometry (ICP) or inductively coupled plasma mass spectrometry (ICP-MS). Three to ten samples of TCP, MgTCP and ZnTCP were subjected to the dissolution test. The data of calcium concentration at the end of the dissolution period were converted to the dissolved amount ( $\mu$ mol) of TCP, MgTCP or ZnTCP on the assumption that the dissolution proceeded congruently. The dissolved amount divided by the dissolution period gave the dissolution rate $(\mu \mathrm{mol} / \mathrm{s})$. The dissolution rate was averaged over every specimen subjected to the dissolution test $(n=3-10)$. The average dissolution rate was divided by that of TCP60, TCP25, 1.0MgTCP or TCP90 to obtain the relative dissolution rate. The relative dissolution rates were used to characterize dissolution behaviors and for comparison with the relative amount of resorption in vitro and in vivo. 


\subsection{Osteoclastic resorption}

Previous data measured at research center A for the volume of osteoclastic resorption pits on the TCP90, 0.5ZnTCP and 1.0ZnTCP disks (Specimens 13-15, respectively) with relative densities of 91-93\% was analyzed - the previous paper reported incorrect relative densities (67-83\%) for the disks [32]. Briefly, the osteoclasts were isolated from unfractionated bone cells in the bones of 10-day-old Japanese white rabbits. Between 1 $\times 10^{4}$ and $3 \times 10^{4}$ mature osteoclasts were obtained from one rabbit. More than $90 \%$ of the cells obtained were tartrate-resistant acid phosphatase (TRAP)-positive and multinucleate (three or more nuclei). The osteoclasts were seeded on the TCP and ZnTCP disks previously placed in each well of a 12-well plate and cultured for 2 hours at $37{ }^{\circ} \mathrm{C}$ to allow them to attach to the disks. After cultivation for 2 hours, $2 \mathrm{ml}$ of $\alpha$-MEM with $10 \%$ FBS and 5\% L-glutamine supplemented with $100 \mathrm{ng} / \mathrm{ml}$ of macrophage colony-stimulation factor (M-CSF) (mouse recombinant, Calbiochem) and $50 \mathrm{ng} / \mathrm{ml}$ of TRANCE (mouse recombinant RANK ligand, TECHNE Co.) were added to each well. The osteoclasts were further cultured for 24 hours at $37{ }^{\circ} \mathrm{C}$. After cultivation for 24 hours, the osteoclasts were removed from the disks by sonication in a $0.25 \mathrm{M} \mathrm{NH}_{4} \mathrm{OH}$ solution. All disks were then dehydrated in a graded series of ethanol concentrations and processed with a critical point dryer. They were subsequently coated with platinum in a cold sputter coater to visualize the resorption pits. The coated disks were examined with a color laser microscope (VK-9500, KEYENCE, Japan) equipped with an image analysis system (VK-9500 analyzer, KEYENCE, Japan). The volumes of 30 randomly selected pits on each of the four disks (120 pits in total) were measured. The pit volumes were averaged over the 120 pits. The average pit volume for $0.5 Z n T C P$ and 1.0ZnTCP was divided by that of the TCP90 to obtain the relative pit volume. The 
relative pit volumes were compared with the relative dissolution rates of corresponding ZnTCP disks measured at research center C.

\subsection{In vivo resorption}

The in vivo resorption study was performed at research center A. Cylindrical implants of TCP60, TCP70, 1.0MgTCP, 1.7MgTCP and 3.4MgTCP (Specimens 8-12, respectively) were implanted perpendicular to the long axis of the femoral diaphysis of skeletally mature New Zealand White rabbits (male, 15 months old, 3.0-3.5 kg in weight) for four weeks. The same group of specimens was implanted bilaterally. After sacrifice, all the bone specimens containing the implants were subjected to undecalcified histological processing except for one pair of bone specimens (right and left) randomly selected from each group for decalcified histological processing. For undecalcified histological processing, the bone specimens were immersed in a $70 \%$ ethanol solution for 1 week for fixation. The bone specimens were stained with Villanueva Bone (VB) solution, embedded in methyl methacrylate (MMA), cut into two or three sections by cutting parallel to the long axis of the implant and ground to $50-\mu \mathrm{m}$-thick undecalcified sections. The resorption of implants was revealed by the rugged external form of the implants on undecalcified sections observed with a stereoscopic microscope (Fig. 1).

The area of resorption lying between the rugged outline and the original outline was measured by image analysis (Image-Pro PLUS, Ver 6.1). From the area of resorption, the apparent resorbed volume of the implant per unit lateral area of the implant (V) was calculated according to a method described elsewhere [33]. The measurement was performed on bone specimens with no femoral fracture, in-process 
implant fracture or deformation. The apparent resorbed volume per cylindrical length of $1 \mathrm{~mm}\left(V_{1}\right)$ was calculated using the following equation:

$$
V_{1}=2 \pi r V\left(\mathrm{~mm}^{3}\right)
$$

where $r$ is the radius of the implant. The net amount of resorbed TCP or MgTCP per cylindrical length of $1 \mathrm{~mm}\left(A_{1}\right)$ was calculated using

$$
A_{1}=D r D V_{1} / 100 M(\mu \mathrm{mol}) \text {, }
$$

where $D r, D$ and $M$ are the relative density of the implant, the density of the TCP or MgTCP and the molecular weight of the TCP or MgTCP, respectively. $V_{1}$ and $A_{1}$ were averaged over every specimen (n=8-10). The average $V_{1}$ and $A_{1}$ were divided by the average $V_{1}$ and $A_{1}$, respectively, of TCP60 or $1.0 \mathrm{MgTCP}$ to obtain relative $V_{1}$ and $A_{1}$. The relative $V_{1}$ and $A_{1}$ were compared with the relative dissolution rates measured at research centers A-I.

For decalcified histological processing, the bone specimens were fixed in $10 \%$ neutral-buffered formalin, decalcified, embedded in paraffin and cut into 5- $\mu \mathrm{m}$-thick sections with the staining of toluidine blue and TRAP to observe the osteoclasts. The number of TRAP-positive cells existing less than $200 \mu \mathrm{m}$ from the implant was measured on 6-16 microscopic images within the section. Thus, the average and standard deviation for each group are those for the 6-16 images from one rabbit. All animal experiments were performed under conditions approved by the Institutional Animal Care and Use Committee of National Institute of Advanced Industrial Science and Technology (AIST) and in accordance with the Guide for the Care and Use of Laboratory Animals of the National Institutes of Health (NIH 1996). 


\subsection{Statistical analysis}

All statistical comparisons were conducted using Student's $t$-tests. The standard

deviations $(\sigma)$ of the relative values, $\overline{X_{1}} / \overline{X_{0}}$, such as the relative dissolution rate, pit

volume, $V_{1}$ and $A_{1}$ were calculated using

$$
\sigma=\sqrt{\left\{-\frac{\overline{x_{1}}}{\left(\overline{x_{0}}\right)^{2}}\right\}^{2} \cdot \sigma_{0}^{2}+\left(\frac{1}{\overline{x_{0}}}\right)^{2} \cdot \sigma_{1}^{2}}
$$

where $\overline{X_{0}}$ and $\overline{X_{1}}$ are average values for groups 0 and 1 , and $\sigma_{0}$ and $\sigma_{1}$ are the standard deviations for groups 0 and 1 , respectively. The significance level was set at p $<0.05$.

\section{Results}

The dissolution curves were almost linear during the dissolution periods at $\mathrm{pH} 4.0$, 5.5 and 7.3 (Fig. 2 and Fig. S6). The calculated dissolution rates represented the slopes of the dissolution curves. The dissolution rate of the same specimen under the same $\mathrm{pH}$ condition varied by up to $600 \%$ depending on the research center and the dissolution conditions such as the solution volume (35-200 mL) and stirring speed (200-450 rpm). However, the relative dissolution rates, i.e., the average dissolution rates of TCP70, TCP25, TCP35, 1.0MgTCP, 1.7MgTCP and 3.4MgTCP relative to that of TCP60, varied by only up to $183 \%$ in spite of the differences in solution volumes, stirring speeds and even $\mathrm{pH}$ (4.0, 5.5 and 7.3) as shown in Figs. 3-6.

The relative dissolution rates had higher sensitivity to a difference in microporosity 
than to a difference in macroporosity. The relative dissolution rates of microporous TCP70 compared with microporous TCP60 were significantly lower than 1.0 except for research center $G$ as shown in Fig. 3. However, the relative dissolution rates of macroporous TCP35 compared with macroporous TCP25 showed no significant difference ( $\mathrm{p}>0.05$ ) from 1.0 except for condition H-2 (Fig. 4). Thus, a 10\% difference in microporosity has a greater effect on the dissolution rate than the same difference in macroporosity.

The relative pit volume and relative dissolution rate decreased with an increase in the zinc content of TCP (Fig. 7). The relative pit volume for 0.5ZnTCP compared with TCP90 was significantly lower than 1.0. Similarly, the relative pit volume for 1.0ZnTCP was significantly lower than both 1.0 and that for $0.5 Z n T C P$. The dissolution rates for 0.5ZnTCP and 1.0ZnTCP compared with TCP90 were significantly lower than 1.0. The relative dissolution rate for $1.0 \mathrm{ZnTCP}$ was not significantly lower than that for $0.5 Z n T C P(p=0.066)$.

The relative pit volumes agreed with the relative dissolution rates without significant differences for both $0.5 \mathrm{ZnTCP}$ and $1.0 \mathrm{ZnTCP}(\mathrm{p}=0.33$ for $0.5 \mathrm{ZnTCP}$ and 0.46 for $1.0 \mathrm{ZnTCP})$.

The apparent resorbed volume in vivo, $V_{1}$, for microporous TCP60, TCP70, 1.0MgTCP, 1.7MgTCP and 3.4MgTCP depended on the relative density and magnesium content. Individual $V_{1}$ values for the same specimen varied by up to $268 \%$. The average value of $V_{1}$ was from 0.25 to $0.39 \mathrm{~mm}^{3}$ (Fig. 8). There was no significant difference in $V_{1}$ between TCP60 and TCP70 $(\mathrm{p}=0.088)$. The TCP60 and TCP70 specimens had 
relative densities of 62 and 72\%, respectively (Table 1). The MgTCP specimens, which had similar relative densities (65-67\%) and different Mg contents, tended to have decreasing $V_{1}$ with increasing Mg content from 1.0 to 3.4 mol\% (1.0MgTCP, 1.7MgTCP and 3.4 MgTCP).

The relative dissolution rate was in good agreement with the relative $V_{1}$ but in poor agreement with the relative $A_{1}$ in the case of the microporous TCP specimens (Fig. 3). The relative dissolution rates of microporous TCP70 compared with microporous TCP60 agreed with the relative $V_{1}$ for TCP70 compared with microporous TCP60 without significant differences $(p=0.54-0.08)$ except for condition $E-1 \quad(p=0.03)$. However, the relative dissolution rates were significantly different from the relative $A_{1}$ under five conditions (A-4, C, D, E-1 and A-6 in Fig. 3).

The relative dissolution rate coincided with the relative $V_{1}$ and $A_{1}$ among the microporous MgTCP specimens. The relative dissolution rates of $1.7 \mathrm{MgTCP}$ and 3.4MgTCP compared with $1.0 \mathrm{MgTCP}$ were in the range from 0.88 to 0.95 and from 0.48 to 0.61 , respectively (Fig. 5). These relative dissolution rates agreed with the relative $V_{1}$ and $A_{1}$ of $1.7 \mathrm{MgTCP}$ and $3.4 \mathrm{MgTCP}$ compared with $1.0 \mathrm{MgTCP}$ without significant differences ( $\mathrm{p}=0.49-0.11$ ) (Fig. 5). However, the relative dissolution rates of 1.0MgTCP, $1.7 \mathrm{MgTCP}$ and 3.4MgTCP compared with TCP60 were all significantly lower than the corresponding relative $V_{1}$ and $A_{1}$ except for condition A-3 for 1.0MgTCP and $\mathrm{H}-1$ for 3.4MgTCP (Fig. 6). More osteoclasts were observed around the 1.0MgTCP, 1.7MgTCP and 3.4MgTCP implants than around TCP60 implants, although the differences were not significant (Fig. 9). 


\section{Discussion}

In the present study, the dissolution tests were designed to test different calcium phosphate phases under a range of undersaturation starting at 1 and ending - for the lowest value - at 0.8 (see supporting data and Table S8) regardless of the specimen. In this range of undersaturation, the dissolution curves were almost linear, which was useful for defining the dissolution rates.

A dissolution rate is a function of both the equilibrium solubility and kinetic factors such as the surface area, particle size, porosity and crystallinity. The resorption of calcium phosphate biomaterials depends on both their equilibrium solubility and kinetic factors $[17,31,34]$. Thus, we focused on measuring the dissolution rate. However, the dissolution rate was unacceptable as a standard index due to large interlaboratory differences. On the other hand, the interlaboratory differences were diminished efficiently by converting the dissolution rate to the relative dissolution rate. The interlaboratory differences in the relative dissolution rates (183\% at maximum) were within the scattering in $V_{1}$ (268\% at maximum) obtained from in vivo experiments. The maximum value of $183 \%$ in interlaboratory difference was obtained in spite of a wide range of differences in solution volumes (35-200 mL), stirring speeds (200-450 rpm) and even $\mathrm{pH}$ (4.0, 5.5 and 7.3). Note that a difference of 1.0 in $\mathrm{pH}$ gives a difference of $660 \%$ in the initial dissolution rate of TCP [27]. Therefore, the relative dissolution rate can be a useful standard index that can be used regardless of a wide range of differences in dissolution conditions. 
The relative dissolution rates agreed with the relative pit volumes for ZnTCPs having different equilibrium solubility. The zinc incorporated in TCP decreases the equilibrium solubility of TCP [33]. The osteoclastic resorption of calcium phosphate is a process of cell-mediated dissolution in an acidic fluid in the resorption pits [19]. The effect of zinc on decreasing the TCP solubility resulted in the same rate of decrease in both the dissolution rate and the volume of osteoclastic resorption pits. Thus, the relative dissolution rates agreed with the relative pit volumes. However, it should be noted that the relative pit volumes (Fig. 7) do not take account of material-mediated differences in the total number of pits or osteoclasts between TCP90, 0.5ZnTCP and 1.0 ZnTCP. The number of resorbing osteoclasts slightly decreases with an increase in the zinc content of TCP in vitro [32]. Thus, the relative dissolution rates multiplied by the total number of osteoclasts or resorption pits would be better correlated to the relative amount of osteoclastic resorption in vitro.

A relative dissolution rate may be useful to predict the amount of resorption of microporous calcium phosphate having different equilibrium solubility when material-mediated differences in biological process are negligible. The effect of $\mathrm{Mg}$ on decreasing the equilibrium solubility of MgTCP has been substantiated [35, 36]. The relative dissolution rate of MgTCP coincided with the relative $V_{1}$ and $A_{1}$ for the MgTCP when the denominator of the relative values belonged to another MgTCP. However, when the denominator belonged to TCP (TCP60), the relative dissolution rate of MgTCP significantly differed from the relative $V_{1}$ and $A_{1}$ for the MgTCP. The discrepancy when the denominator belongs to TCP arises from differences in the material-mediated biological process between TCP and MgTCP, as was tentatively 
shown by the increased number of osteoclasts around the MgTCP implants compared with TCP implants (Fig. 9). As a result, the relative $V_{1}$ and $A_{1}$ for the MgTCP compared with TCP resulted from two different effects of Mg incorporated in the TCP lattice: the effect of Mg on increasing the resorption of TCP and the effect of Mg on decreasing the equilibrium solubility of TCP. The former effect has some link with the dose-dependent effects of Mg on the differentiation and function of osteoclasts and macrophages [37, 38]. Thus, the relative dissolution rate may be useful when material-mediated differences in biological process are negligible. Note that the present study demonstrates that a small amount of Mg incorporated in the TCP lattice increases the resorption of TCP in vivo.

The validity of using the relative dissolution rate for predicting the resorption of pure TCP with different porosity remains to be clarified further. In the case of ZnTCP and MgTCP, the specimens had the same porosity and different equilibrium solubility while, in the case of pure TCP, the specimens had the same solubility and different porosity. Regarding the microporosity of TCP, it is reported that an increase in the microporosity of TCP has a greater effect on resorption than an increase in macroporosity [3, 39, 40]. These phenomena are qualitatively similar to the effect of microporosity and macroporosity on the dissolution rates. However, in the previous and present studies, in vivo resorption was quantified by measuring the resorbed area or volume histomorphometrically. The measured area or volume such as $V_{1}$ inherently includes that of micropores that existed in the resorbed portion. Thus, the net amount of resorbed TCP is not $V_{1}$ but $A_{1}$. On the other hand, the difference in $A_{1}$ was statistically insignificant between microporous TCP60 and TCP70. Thus, it cannot be 
ruled out that the agreement between the relative dissolution rate and relative $V_{1}$ for microporous TCP was an accidental result that arose from the combined effects of the latent micropore volume and some biological factor that maintains a constant calcium metabolism. To address the above issue, the quantification of $A_{1}$ with higher precision is required. Regarding the macroporous TCP, no in vivo study was carried out in the present study. Although the $10 \%$ difference in macroporosity gave a value of nearly 1.0 for the relative dissolution rate, it is yet to be clarified whether the $10 \%$ difference in macroporosity gives a value of 1.0 for the relative $V_{1}$ and $A_{1}$.

Other limitations of the present study are (i) its uncertain applicability to other calcium phosphates and (ii) that the protocol for the dissolution tests needs to be improved further. The present dissolution test conditions may not be able to predict the in vivo resorption of calcium phosphate ceramics different from those tested in the present study. The correlation between the relative dissolution rates and in vivo resorption needs to be studied for individual calcium phosphate ceramics. In other words, an assay has to be established for every ceramic to be analyzed. In addition, the protocol of dissolution tests has to be improved to obtain higher precision and better reproducibility of the measured values. Means of improvement include the pretreatment of specimens before immersion, the method of validation, the way the specimen is held in the solution and the way of integration of the effect of particle disintegration [41, 42]. One institute (I) reported the reduced wettability of specimens, probably due to the natural and progressive adsorption of organic hydrophobic moieties in air, which was recovered by heat treatment before immersion. 


\section{Conclusion}

An in vitro dissolution test method was proposed to estimate the relative rate of resorption of calcium-phosphate-based ceramics. According to this method, calcium phosphates were dissolved in a neutral or slightly acidic buffer solution free of calcium and phosphate ions. Since the calcium phosphates dissolved linearly over the first 5-180 min, the relative dissolution rates were calculated without difficulty and compared with each other. The results suggest that the measurement of the relative dissolution rate in vitro is useful as a standard test procedure to predict relative amounts of resorption for calcium-phosphate-based ceramics having different solubility, provided that material factors, such as a small amount of Mg doping ions, do not affect the biological process, such as the density or activity of resorbing cells. Further study is required to clarify whether the relative dissolution rate is predictive of relative amounts of resorption for calcium-phosphate-based ceramics having the same solubility but different porous characteristics.

\section{Disclosures}

There is no potential conflict of interest for this study

\section{Acknowledgements}

We acknowledge Koji Senda, Shu Ihara and Shunxin Guo at Waseda University; Tokoha Sakurai and Kazuko Yoshiyuki at National Institute of Advanced Industrial Science and Technology; Dr. Yasutaka Yamada at University of Tsukuba; Jun Fukasawa at Meiji University; and Reto Luginbuehl, Benjamin Andreatta and Dmitriy Alexeev at RMS Foundation for their technical assistance. Lídia Ágata de Sena acknowledges CNPq for 
the fellowship (PROMETRO/CNPq 370823/2011-7). This study was supported in part by Special Coordination Funds for Promoting Science and Technology (Japan).

\section{References}

[1] Wiltfang J, Merten HA, Schlegel KA, Schultze-Mosgau S, Kloss FR, Rupprecht S, et al. Degradation characteristics of alpha and beta tri-calcium-phosphate (TCP) in minipigs. Journal of biomedical materials research 2002;63:115-21.

[2] Walsh WR, Vizesi F, Michael D, Auld J, Langdown A, Oliver R, et al. beta-TCP bone graft substitutes in a bilateral rabbit tibial defect model. Biomaterials 2008;29:266-71.

[3] von Doernberg MC, von Rechenberg B, Bohner M, Grunenfelder S, van Lenthe GH, Muller R, et al. In vivo behavior of calcium phosphate scaffolds with four different pore sizes. Biomaterials 2006;27:5186-98.

[4] Cameron HU. Tricalcium phosphate as a bone graft substitute. Contemporary orthopaedics 1992;25:506-8.

[5] McAndrew MP, Gorman PW, Lange TA. Tricalcium phosphate as a bone graft substitute in trauma: preliminary report. Journal of orthopaedic trauma 1988;2:333-9.

[6] Thorwarth M, Schultze-Mosgau S, Kessler P, Wiltfang J, Schlegel KA. Bone regeneration in osseous defects using a resorbable nanoparticular hydroxyapatite. J Oral Maxil Surg 2005;63:1626-33.

[7] Knaack D, Goad ME, Aiolova M, Rey C, Tofighi A, Chakravarthy P, et al. Resorbable calcium phosphate bone substitute. Journal of biomedical materials research 1998;43:399-409.

[8] del Real RP, Ooms E, Wolke JG, Vallet-Regi M, Jansen JA. In vivo bone response to porous calcium phosphate cement. Journal of biomedical materials research Part A 2003;65:30-6.

[9] Herron S, Thordarson DB, Winet H, Luk A, Bao JY. Ingrowth of bone into absorbable bone cement: an in vivo microscopic evaluation. American journal of orthopedics 2003;32:581-4.

[10] Frankenburg EP, Goldstein SA, Bauer TW, Harris SA, Poser RD. Biomechanical and histological evaluation of a calcium phosphate cement. J Bone Joint Surg Am 1998;80A:1112-24. 
[11] Malard O, Bouler JM, Guicheux J, Heymann D, Pilet P, Coquard C, et al. Influence of biphasic calcium phosphate granulometry on bone ingrowth, ceramic resorption, and inflammatory reactions: preliminary in vitro and in vivo study. Journal of biomedical materials research 1999;46:103-11.

[12] Fellah BH, Delorme B, Sohier J, Magne D, Hardouin P, Layrolle P. Macrophage and osteoblast responses to biphasic calcium phosphate microparticles. Journal of biomedical materials research Part A 2010;93:1588-95.

[13] Chen Z, Wu C, Gu W, Klein T, Crawford R, Xiao Y. Osteogenic differentiation of bone marrow MSCs by beta-tricalcium phosphate stimulating macrophages via BMP2 signalling pathway. Biomaterials 2014;35:1507-18.

[14] Davison NL, Gamblin AL, Layrolle P, Yuan H, de Bruijn JD, Barrere-de Groot F. Liposomal clodronate inhibition of osteoclastogenesis and osteoinduction by submicrostructured beta-tricalcium phosphate. Biomaterials 2014;35:5088-97.

[15] Zhang ZY, Egana JT, Reckhenrich AK, Schenck TL, Lohmeyer JA, Schantz JT, et al. Cell-based resorption assays for bone graft substitutes. Acta biomaterialia 2012;8:13-9.

[16] Winkler T, Hoenig E, Gildenhaar R, Berger G, Fritsch D, Janssen R, et al. Volumetric analysis of osteoclastic bioresorption of calcium phosphate ceramics with different solubilities. Acta biomaterialia 2010;6:4127-35.

[17] Bohner M, Baumgart F. Theoretical model to determine the effects of geometrical factors on the resorption of calcium phosphate bone substitutes. Biomaterials 2004;25:3569-82.

[18] Bashoor-Zadeh M, Baroud G, Bohner M. Simulation of the in vivo resorption rate of beta-tricalcium phosphate bone graft substitutes implanted in a sheep model. Biomaterials 2011;32:6362-73.

[19] Silver IA, Murrills RJ, Etherington DJ. Microelectrode Studies on the Acid Microenvironment beneath Adherent Macrophages and Osteoclasts. Exp Cell Res 1988;175:266-76.

[20] Rodan GA, Martin TJ. Therapeutic approaches to bone diseases. Science 2000;289:1508-14. 
[21] Cech P, Lehrer RI. Phagolysosomal pH of human neutrophils. Blood 1984;63:88-95.

[22] Nyberg K, Johansson U, Johansson A, Camner P. Phagolysosomal pH in alveolar macrophages. Environmental health perspectives 1992;97:149-52.

[23] Mindell JA. Lysosomal acidification mechanisms. Annual review of physiology 2012;74:69-86.

[24] Tang RK, Hass M, Wu WJ, Gulde S, Nancollas GH. Constant composition dissolution of mixed phases II. Selective dissolution of calcium phosphates. J Colloid Interf Sci 2003;260:379-84.

[25] Tang RK, Wu WJ, Haas M, Nancollas GH. Kinetics of dissolution of beta-tricalcium phosphate. Langmuir 2001;17:3480-5.

[26] Chow LC, Markovic M, Takagi S. A dual constant-composition titration system as in vitro resorption model for comparing dissolution rates of calcium phosphates biomaterials. J Biomed Mater Res B 2003;65B:245-51.

[27] Bohner M, Lemaitre J, Ring TA. Kinetics of dissolution of beta-tricalcium phosphate. J Colloid Interf Sci 1997;190:37-48.

[28] ASTM F 1926/F 1926M - 08 Standard Test Method for Evaluation of the Environmental Stability of Calcium Phosphate Granules, Fabricated Forms, and Coatings.

[29] Ducheyne P, Radin S, King L. The effect of calcium phosphate ceramic composition and structure on in vitro behavior. I. Dissolution. Journal of biomedical materials research 1993;27:25-34.

[30] Bloebaum RD, Lundeen GA, Bachus KN, Ison I, Hofmann AA. Dissolution of particulate hydroxyapatite in a macrophage organelle model. Journal of biomedical materials research 1998;40:104-14.

[31] Schaefer S, Detsch R, Uhl F, Deisinger U, Ziegler G. How Degradation of Calcium Phosphate Bone Substitute Materials is influenced by Phase Composition and Porosity. Adv Eng Mater 2011;13:342-50.

[32] Yamada Y, Ito A, Kojima H, Sakane M, Miyakawa S, Uemura T, et al. Inhibitory effect of Zn2+ in zinc-containing beta-tricalcium phosphate on resorbing activity of mature osteoclasts. Journal of biomedical materials research Part A 2008;84:344-52. 
[33] Ito A, Kawamura H, Miyakawa S, Layrolle P, Kanzaki N, Treboux G, et al. Resorbability and solubility of zinc-containing tricalcium phosphate. Journal of biomedical materials research 2002;60:224-31.

[34] Szpalski M, Gunzburg R. Applications of calcium phosphate-based cancellous bone void fillers in trauma surgery. Orthopedics 2002;25:S601-S9.

[35] Verbeeck RMH, Debruyne PAM, Driessens FCM, Terpstra RA, Verbeek F. Solubility Behavior of Mg-Containing Beta-Ca3(Po4)2. B Soc Chim Belg 1986;95:455-76.

[36] Li X, Ito A, Sogo Y, Wang XP, LeGeros RZ. Solubility of Mg-containing beta-tricalcium phosphate at 25 degrees C. Acta biomaterialia 2009;5:508-17.

[37] Wu L, Luthringer BJ, Feyerabend F, Schilling AF, Willumeit R. Effects of extracellular magnesium on the differentiation and function of human osteoclasts. Acta biomaterialia 2014.

[38] Chen ZT, Mao XL, Tan LL, Friis T, Wu CT, Crawford R, et al. Osteoimmunomodulatory properties of magnesium scaffolds coated with beta-tricalcium phosphate. Biomaterials 2014;35:8553-65.

[39] Klein CP, de Groot K, Driessen AA, van der Lubbe HB. A comparative study of different beta-whitlockite ceramics in rabbit cortical bone with regard to their biodegradation behaviour. Biomaterials 1986;7:144-6.

[40] Yokozeki H, Hayashi T, Nakagawa T, Kurosawa H, Shibuya K, Ioku K. Influence of surface microstructure on the reaction of the active ceramics in vivo. Journal of materials science Materials in medicine 1998;9:381-4.

[41] Kalita SJ, Bhatt HA, Dhamne A. MgO-Na2O-P2O5-based sintering additives for tricalcium phosphate bioceramics. J Am Ceram Soc 2006;89:875-81.

[42] Kalita SJ, Bhatt HA. Nanocrystalline hydroxyapatite doped with magnesium and zinc: Synthesis and characterization. Mat Sci Eng C-Bio S 2007;27:837-48. 


\section{Tables}

Table 1 Specimens used in the present study

Footnotes for Table 1;

\# Parentheses mean the diameters of the non-resorbable biphasic portion at both ends of the cylinder.

$\S$ dis., in vivo and ost. indicate dissolution, in vivo and osteoclastic resorption studies, respectively.

Table 2 Participating research centers, specimens used and dissolution conditions

Footnotes for Table 2;

\# The letters indicate the individual research centers while the numbers indicate dissolution conditions in the center.

$\S$ See Table 1 .

^ $\mathrm{Ph}$, Ac and $\mathrm{Tr}$ indicate $0.05 \mathrm{M}$ potassium hydrogen phthalate, $0.08 \mathrm{M}$ acetic acid-sodium acetate and $0.05 \mathrm{M}$ Tris-HCl buffers, respectively.

* “Elect.” indicates measurement using a calcium-ion-selective electrode. 


\section{Figure captions}

Figure 1 Rugged external form of TCP60 (Specimen 8) showing resorption in the implantation period of 4 weeks.

Figure 2 Dissolution curves for microporous TCP60 (Specimen 3) at pH 5.5 measured in different research centers and under different conditions. The plots are presented as mean \pm SD. The number of specimens was 4 or 5 .

Figure 3 Relative dissolution rates, relative apparent resorbed volume $\left(V_{1}\right)$ and relative net resorbed amount $\left(A_{1}\right)$ for microporous TCP70 (Specimens 4 and 9) compared with TCP60 (Specimens 3 and 8). The data are presented as mean \pm SD. The number of samples was 3, 4, 5 or 8 in the dissolution tests. The numbers of samples were 10 for the relative $V_{1}$ and $A_{1}$.

Figure 4 Relative dissolution rates for macroporous TCP25 and TCP35 (Specimens 1 and 2) compared with TCP60 (Specimen 3) and TCP25. The data are presented as mean \pm SD. The number of samples was 4,5 or 8 .

Figure 5 Relative dissolution rates, relative apparent resorbed volume $\left(V_{1}\right)$ and relative net resorbed amount $\left(A_{1}\right)$ for microporous 1.7MgTCP (Specimens 6 and 11) and 3.4MgTCP (Specimens 7 and 12) compared with 1.0MgTCP (Specimens 5 and 10). The data are presented as mean \pm SD. The number of samples was 5 in the dissolution tests. The number of samples was 9 for $1.7 \mathrm{MgTCP}$ and 10 for $3.4 \mathrm{MgTCP}$ in the in vivo tests. 
Figure 6 Relative dissolution rates, relative apparent resorbed volume $\left(V_{1}\right)$ and relative net resorbed amount $\left(A_{1}\right)$ for microporous 1.0MgTCP (Specimens 5 and 10), 1.7MgTCP (Specimens 6 and 11) and 3.4MgTCP (Specimens 7 and 12) compared with microporous TCP60 (Specimens 3 and 8). The data are presented as mean $\pm \mathrm{SD}$. The number of samples was 4,5 or 8 in the dissolution tests. The number of samples was 8 for 1.0MgTCP, 9 for $1.7 \mathrm{MgTCP}$ and 10 for $3.4 \mathrm{MgTCP}$ in the in vivo tests.

Figure 7 Relative pit volumes and relative dissolution rates for 0.5ZnTCP (Specimen 14) and 1.0ZnTCP (Specimen 15) compared with TCP90 (Specimen 13). The data are presented as mean \pm SD. The number of resorption pits was 120 , which were randomly selected from four disks with 30 pits per disk. The number of disks was 10 in the dissolution tests.

Figure 8 Apparent resorbed volume $\left(V_{1}\right)$ of TCP and MgTCP implants (Specimens 8-12). The data are presented as mean \pm SD. The number of samples was 8 for 1.0MgTCP, 9 for TCP60 and 1.7MgTCP, and 10 for TCP70 and 3.4MgTCP.

Figure 9 Numbers of TRAP-positive cells around TCP and MgTCP implants (A) and histological sections showing TRAP-positive cells around TCP60, 1.7MgTCP and 3.4MgTCP implants (B). "b” indicates bone. The data are presented as mean $\pm \mathrm{SD}$. The mean and SD for each group are those for the 6-16 microscopic images from one rabbit. 
Table 1 Specimens used in the present study

\begin{tabular}{|c|c|c|c|c|c|c|c|c|}
\hline $\begin{array}{l}\text { Specimen } \\
\text { No. }\end{array}$ & Notation & $\begin{array}{c}\text { Mg or Zn } \\
\text { content } \\
\text { (mol\%) }\end{array}$ & $\begin{array}{l}\text { Relative } \\
\text { density } \\
\text { (\%) }\end{array}$ & $\begin{array}{c}\text { Macro- or } \\
\text { micro- } \\
\text { porous }\end{array}$ & Shape & $\begin{array}{l}\text { Diameter }^{\#} \\
(\mathrm{~mm})\end{array}$ & $\begin{array}{l}\text { Length or } \\
\text { thickness } \\
(\mathrm{mm})\end{array}$ & Study ${ }^{\S}$ \\
\hline 1 & ТСР25 & 0 & $25.8 \pm 0.3$ & macro & block & $5.02 \pm 0.03$ & $4.52 \pm 0.02$ & dis. \\
\hline 2 & ТСР35 & 0 & $35.1 \pm 0.7$ & macro & block & $4.99 \pm 0.02$ & $4.52 \pm 0.03$ & dis. \\
\hline 3 & TCP60 & 0 & $63 \pm 1$ & micro & cylinder & $2.43 \pm 0.03$ & $11.3 \pm 0.3$ & dis. \\
\hline 4 & TCP70 & 0 & $74 \pm 1$ & micro & cylinder & $2.44 \pm 0.02$ & $11.2 \pm 0.2$ & dis. \\
\hline 5 & 1.0MgTCP & $1.0 \mathrm{Mg}$ & $68 \pm 1$ & micro & cylinder & $2.43 \pm 0.01$ & $10.8 \pm 0.1$ & dis. \\
\hline 6 & 1.7MgTCP & $1.7 \mathrm{Mg}$ & $64 \pm 1$ & micro & cylinder & $2.48 \pm 0.01$ & $11.1 \pm 0.1$ & dis. \\
\hline 7 & 3.4MgTCP & $3.4 \mathrm{Mg}$ & $62 \pm 1$ & micro & cylinder & $2.45 \pm 0.01$ & $11.3 \pm 0.3$ & dis. \\
\hline 8 & TCP60 & 0 & $62 \pm 1$ & micro & cylinder & $2.41 \pm 0.03(2.50 \pm 0.03)$ & $11.1 \pm 0.3$ & in vivo \\
\hline 9 & TCP70 & 0 & $72 \pm 1$ & micro & cylinder & $2.45 \pm 0.01(2.52 \pm 0.01)$ & $11.2 \pm 0.1$ & in vivo \\
\hline 10 & 1.0MgTCP & $1.0 \mathrm{Mg}$ & $67 \pm 1$ & micro & cylinder & $2.43 \pm 0.01(2.37 \pm 0.02)$ & $11.2 \pm 0.1$ & in vivo \\
\hline 11 & 1.7MgTCP & $1.7 \mathrm{Mg}$ & $65 \pm 1$ & micro & cylinder & $2.48 \pm 0.01(2.37 \pm 0.01)$ & $11.4 \pm 0.1$ & in vivo \\
\hline 12 & 3.4MgTCP & $3.4 \mathrm{Mg}$ & $67 \pm 1$ & micro & cylinder & $2.45 \pm 0.01(2.34 \pm 0.02)$ & $11.2 \pm 0.1$ & in vivo \\
\hline 13 & ТСР90 & 0 & $92 \pm 1$ & micro & disk & $13.53 \pm 0.02$ & $0.90 \pm 0.02$ & ost. dis. \\
\hline 14 & $0.5 \mathrm{ZnTCP}$ & $0.5 \mathrm{Zn}$ & $93 \pm 1$ & micro & disk & $13.45 \pm 0.02$ & $0.89 \pm 0.02$ & ost. dis. \\
\hline 15 & 1.0ZnTCP & $1.0 \mathrm{Zn}$ & $91 \pm 1$ & micro & disk & $13.56 \pm 0.02$ & $0.91 \pm 0.02$ & ost. dis. \\
\hline
\end{tabular}

\# Parentheses mean the diameters of the non-resorbable biphasic portion at both ends of the cylinder.

$\S$ dis., in vivo and ost. indicate dissolution, in vivo and osteoclastic resorption studies, respectively. 
Table 2 Participating research centers, specimens used and dissolution conditions

\begin{tabular}{|c|c|c|c|c|c|c|c|c|c|c|c|}
\hline \multirow{2}{*}{$\begin{array}{l}\text { Research } \\
\text { center \& } \\
\text { conditions }\end{array}$} & \multirow{2}{*}{$\begin{array}{l}\text { Specimen } \\
\text { Nos. }{ }^{8}\end{array}$} & \multicolumn{3}{|c|}{ Solution } & \multirow{2}{*}{$\begin{array}{c}\text { Temp. } \\
\left({ }^{\circ} \mathrm{C}\right)\end{array}$} & \multirow{2}{*}{$\begin{array}{l}\text { Time } \\
\text { (min) }\end{array}$} & \multirow{2}{*}{$\begin{array}{l}\text { Rotation } \\
\text { speed of } \\
\text { stirring } \\
\text { bar (rpm) }\end{array}$} & \multirow{2}{*}{ Method ${ }^{*}$} & \multicolumn{3}{|c|}{ Collection of solution } \\
\hline & & Buff." & $\mathrm{pH}$ & $\begin{array}{l}\text { Vol. or } \\
\text { weight }\end{array}$ & & & & & $\begin{array}{c}\text { Interval } \\
\text { (min) }\end{array}$ & $\begin{array}{l}\text { Vol. } \\
\text { (mL) }\end{array}$ & $\begin{array}{l}\text { Replenish- } \\
\text { ment (mL) }\end{array}$ \\
\hline A-1 & $3-7$ & $\mathrm{Ph}$ & 4.0 & $35 \mathrm{~mL}$ & $25 \pm 2$ & 5 & $430-450$ & ICP & 5 & 1 & 1 \\
\hline A-2 & $3-7$ & $\mathrm{Ph}$ & 4.0 & $35 \mathrm{~mL}$ & $25 \pm 2$ & 30 & $430-450$ & ICP & 5 & 1 & 1 \\
\hline A-3 & $3-7$ & Ac & 5.5 & $35 \mathrm{~mL}$ & $25 \pm 2$ & 180 & $430-450$ & Elect. & & & \\
\hline A-4 & $1-7$ & Ac & 5.5 & $35 \mathrm{~mL}$ & $25 \pm 2$ & 30 & $430-450$ & Elect. & & & \\
\hline A-5 & 3,4 & $\operatorname{Tr}$ & 7.3 & $200 \mathrm{~mL}$ & $37 \pm 1$ & 300 & 200 & ICP & 60 & 5 & 5 \\
\hline A-6 & $3,4,7$ & $\operatorname{Tr}$ & 7.3 & $35 \mathrm{~mL}$ & $25 \pm 2$ & 30 & $430 \pm 15$ & Elect. & & & \\
\hline B & $3,4,7$ & Ac & 5.5 & $100 \mathrm{~mL}$ & $25 \pm 2$ & 30 & $430 \pm 15$ & Elect. & & & \\
\hline $\mathrm{C}$ & 3, 4, 7, & Ac & 5.5 & $35 \mathrm{~mL}$ & $25 \pm 2$ & 30 & $430 \pm 15$ & Elect. & & & \\
\hline $\mathrm{C}$ & $13-15$ & Ac & 5.5 & $35 \mathrm{~mL}$ & $25 \pm 2$ & 30 & $430 \pm 15$ & Elect. & & & \\
\hline $\mathrm{D}$ & $3,4,7$ & Ac & 5.5 & $60 \mathrm{~mL}$ & $25 \pm 2$ & 30 & $430 \pm 15$ & Elect. & & & \\
\hline E-1 & $3,4,7$ & Ac & 5.5 & $60 \mathrm{~mL}$ & $25 \pm 2$ & 30 & $430 \pm 15$ & Elect. & & & \\
\hline E-2 & $3,4,7$ & $\operatorname{Tr}$ & 7.3 & $60 \mathrm{~mL}$ & $25 \pm 2$ & 30 & $430 \pm 15$ & Elect. & & & \\
\hline F & 3,7 & Ac & 5.5 & $80 \mathrm{~mL}$ & $26-32$ & 30 & $430 \pm 15$ & Elect. & & & \\
\hline G & $1-4,7$ & $\mathrm{Ph}$ & 4.0 & $70 \mathrm{~mL}$ & $25 \pm 1$ & 30 & 380 & Elect. & & & \\
\hline $\mathrm{H}-1$ & $3,4,7$ & $\mathrm{Ph}$ & 4.0 & $60 \mathrm{~mL}$ & $25 \pm 2$ & 30 & $417-420$ & AAS & 5 & 1 & 1 \\
\hline $\mathrm{H}-2$ & 1,2 & $\mathrm{Ph}$ & 4.0 & $40,35 \mathrm{~mL}$ & $25 \pm 2$ & 30,18 & $346-348$ & AAS & 5,3 & 1 & 1 \\
\hline I & $1-4,7$ & Ac & 5.5 & $100 \mathrm{~g}$ & $25 \pm 2$ & 30 & 300 & ICP-MS & 5 & 1 & 0 \\
\hline
\end{tabular}

\# The letters indicate the individual research centers while the numbers indicate dissolution conditions in the center.

\& See Table 1.

${ }^{\text {I }} \mathrm{Ph}$, Ac and Tr indicate $0.05 \mathrm{M}$ potassium hydrogen phthalate, $0.08 \mathrm{M}$ acetic acid-sodium acetate and 0.05 M Tris-HCl buffers, respectively.

* “Elect.” indicates measurement using a calcium-ion-selective electrode. 


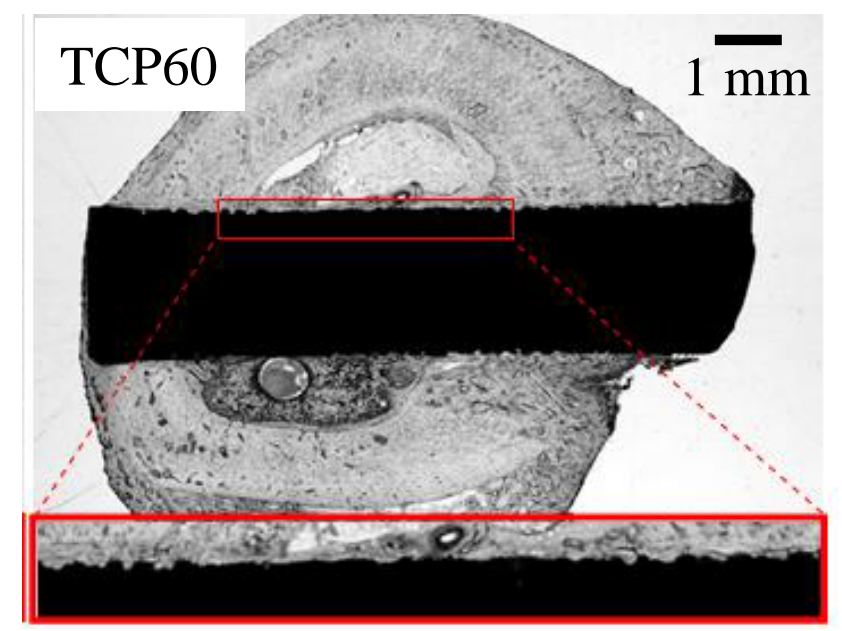

Figure 1 


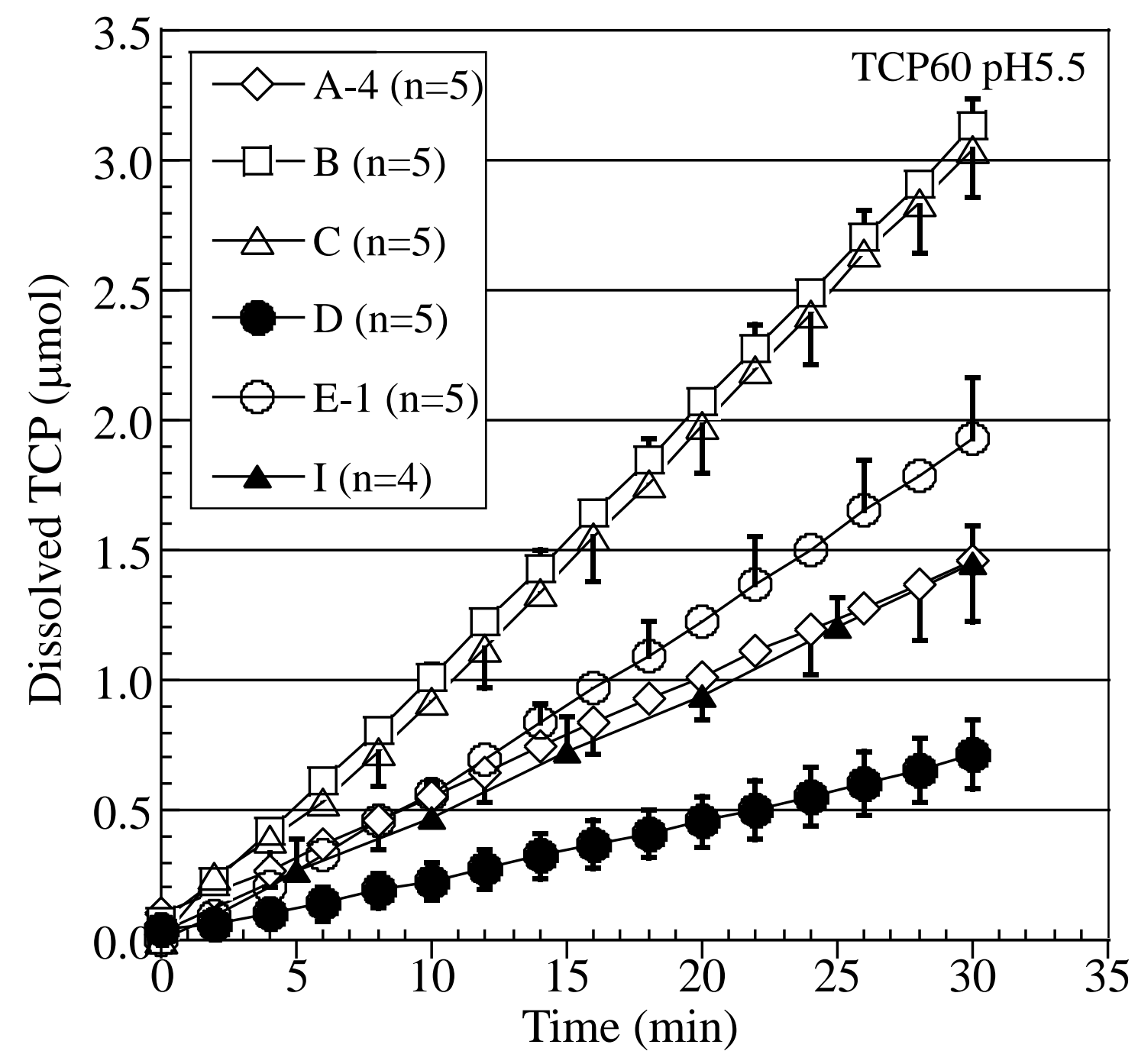

Figure 2 


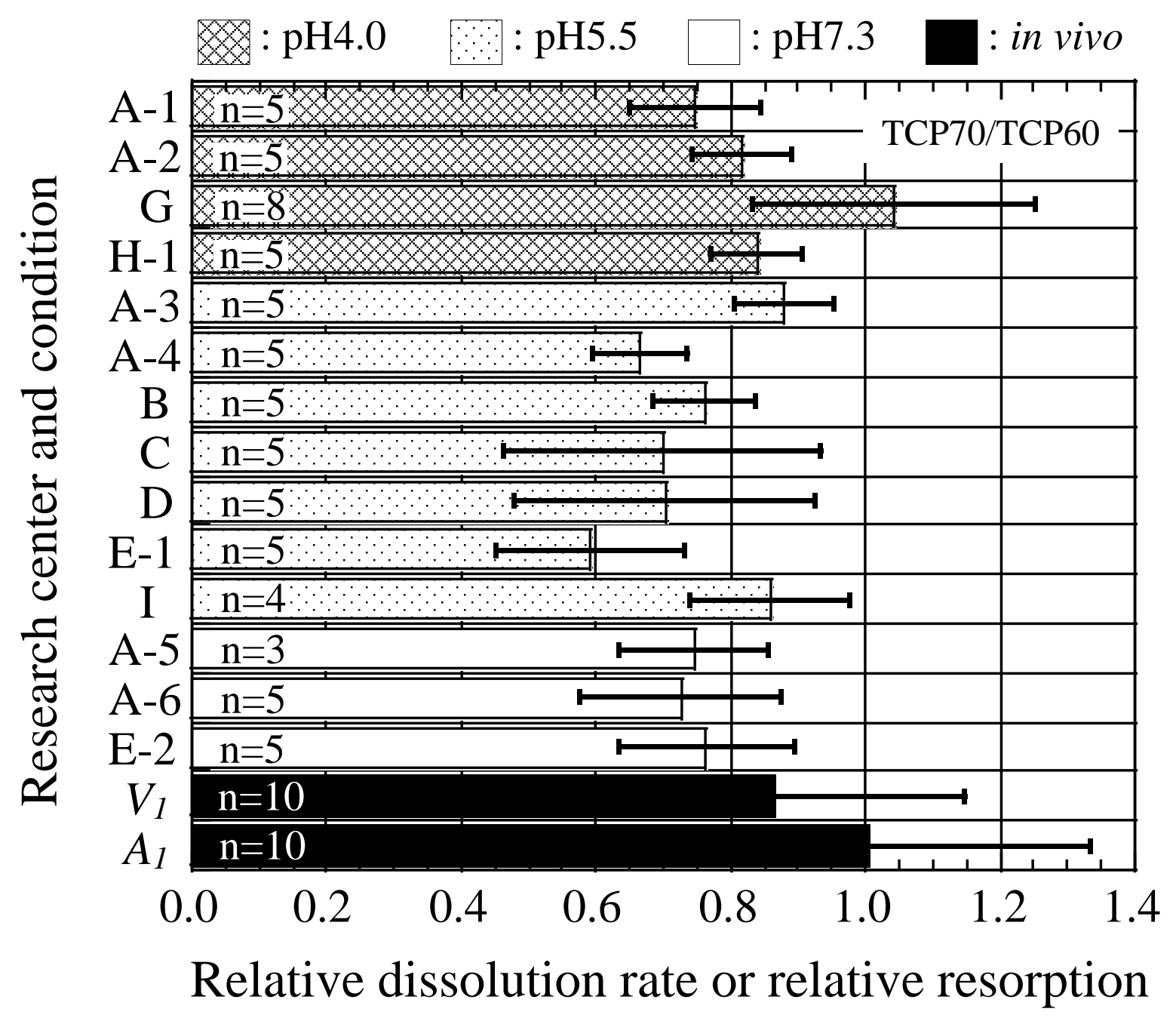

Figure 3 


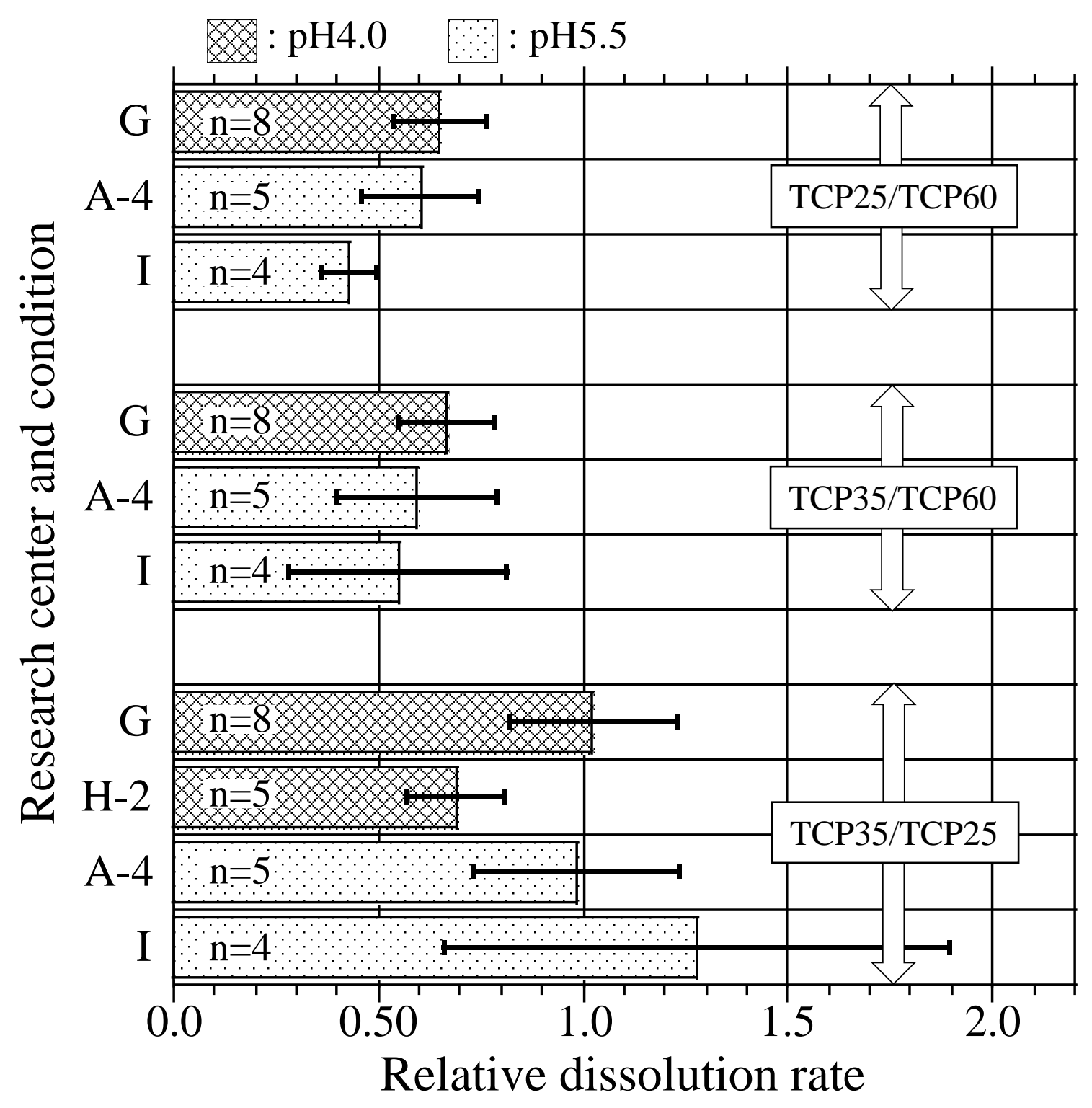

Figure 4 


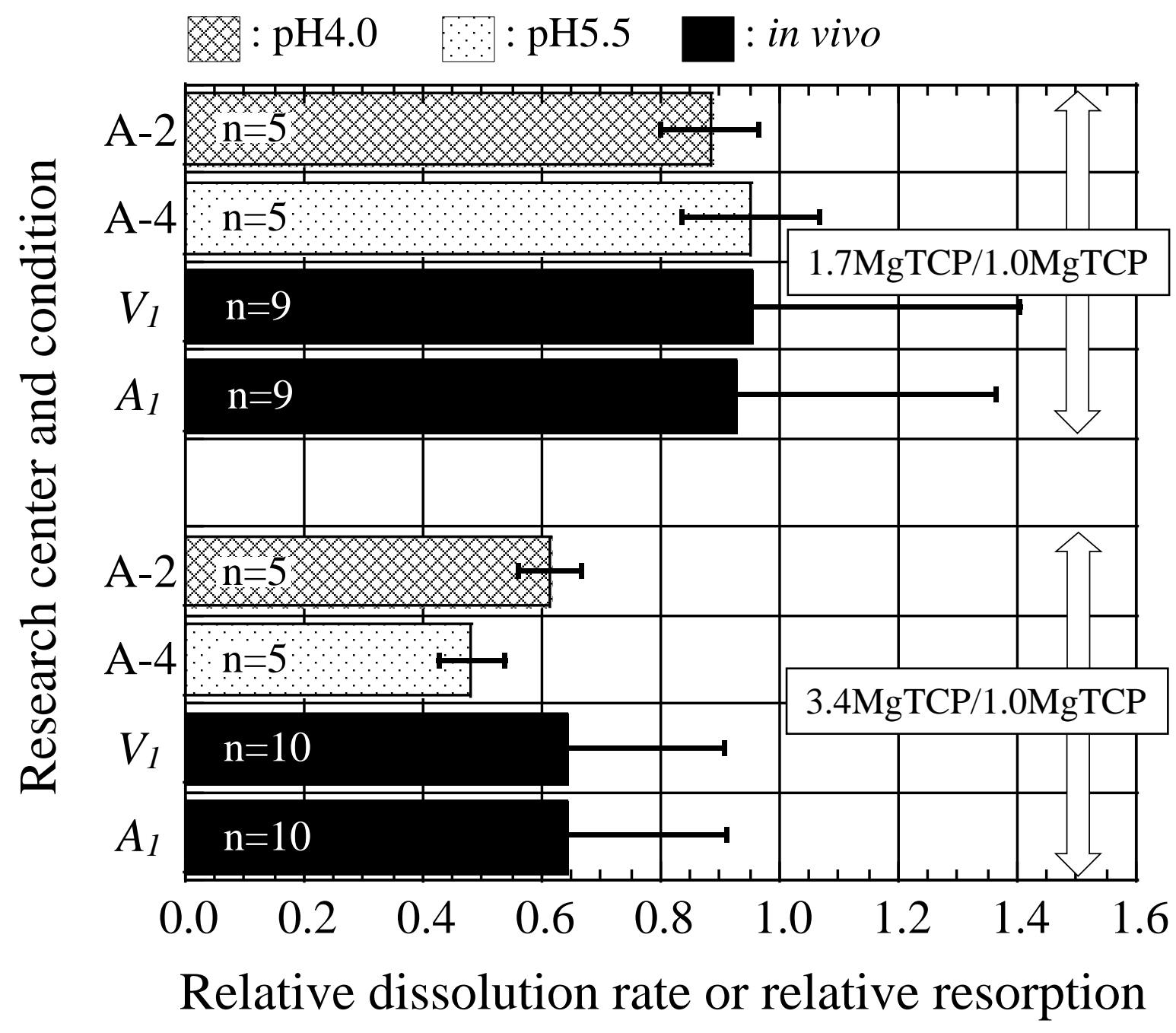

Figure 5 


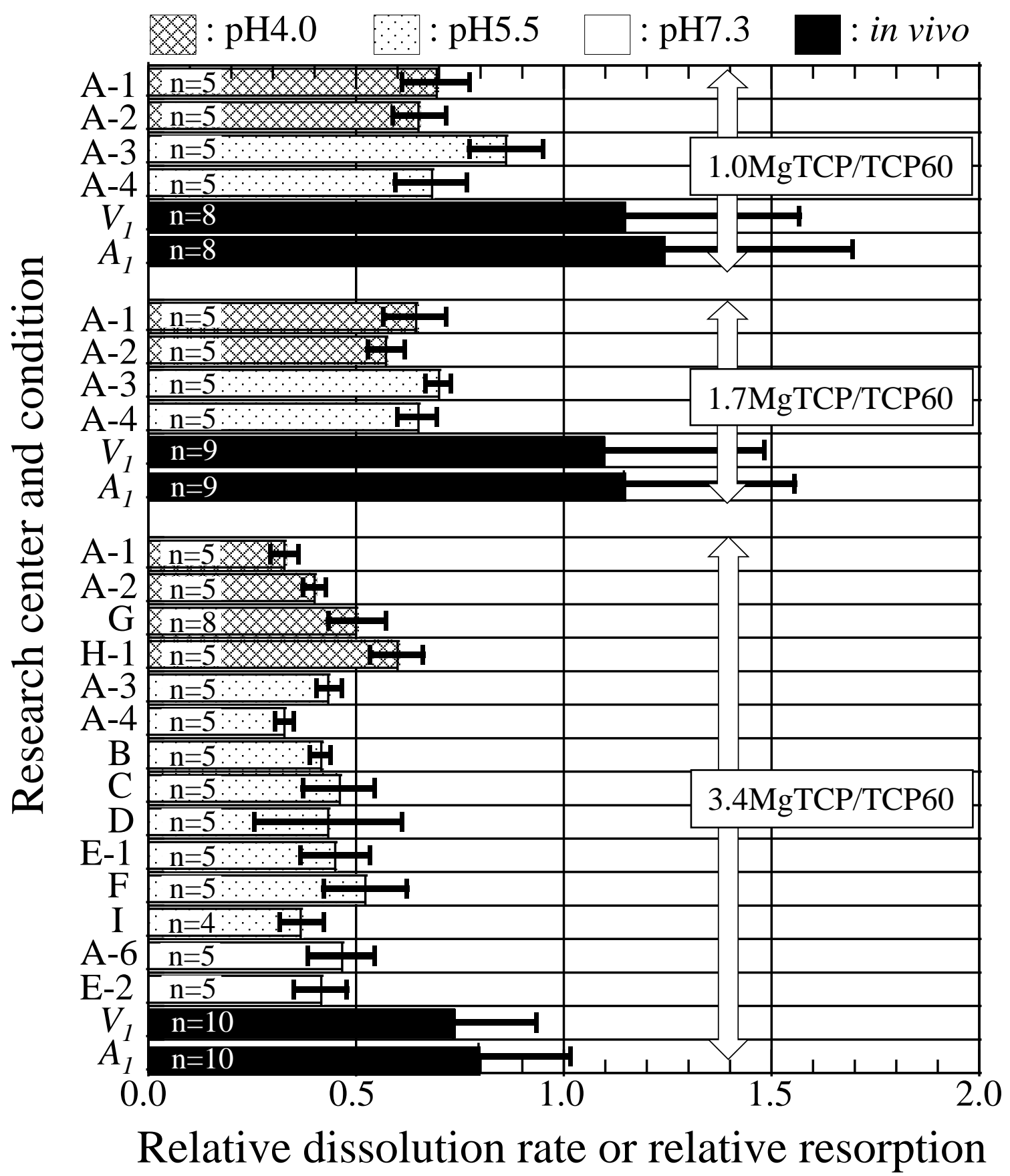

Figure 6 


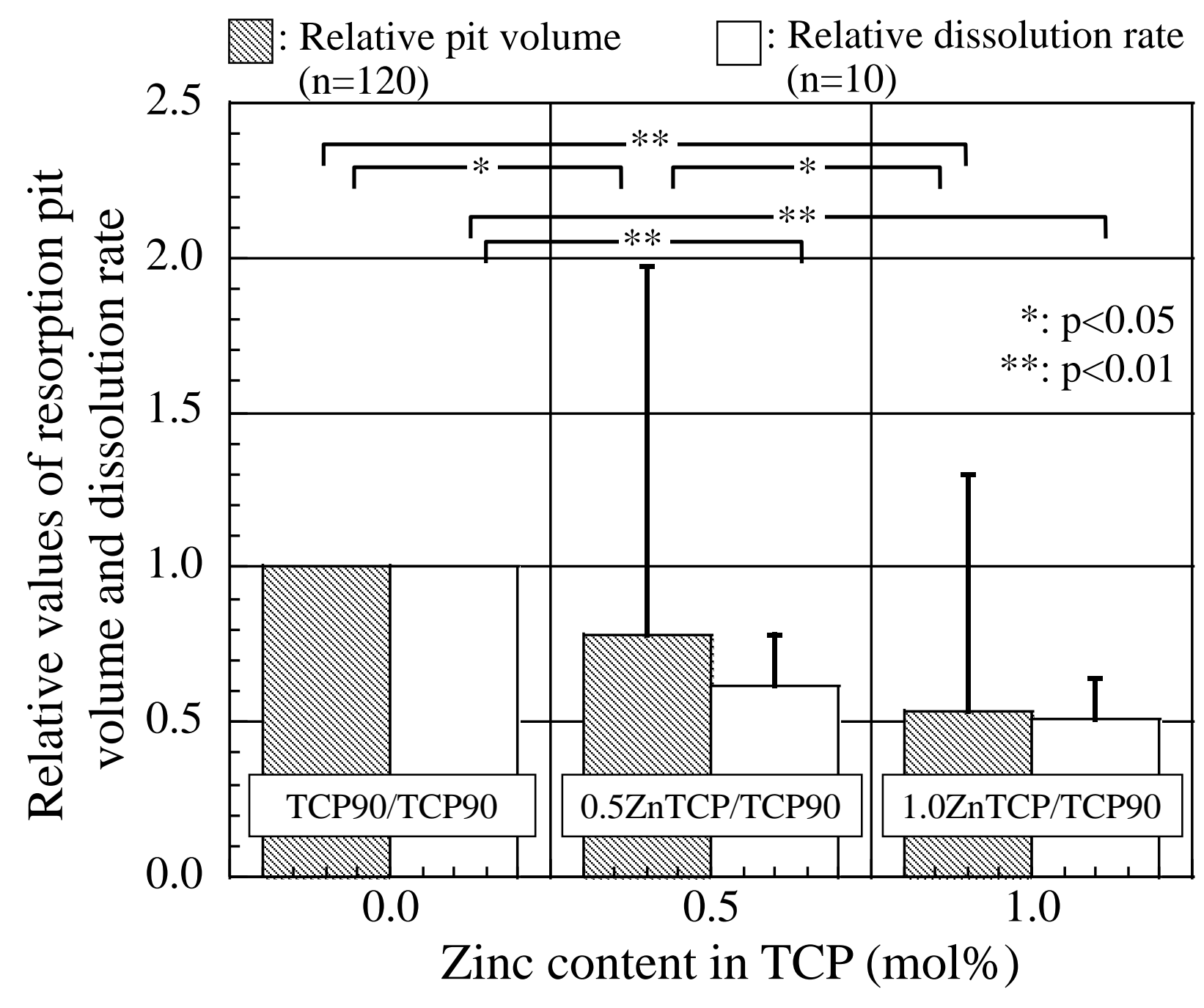

Figure 7 


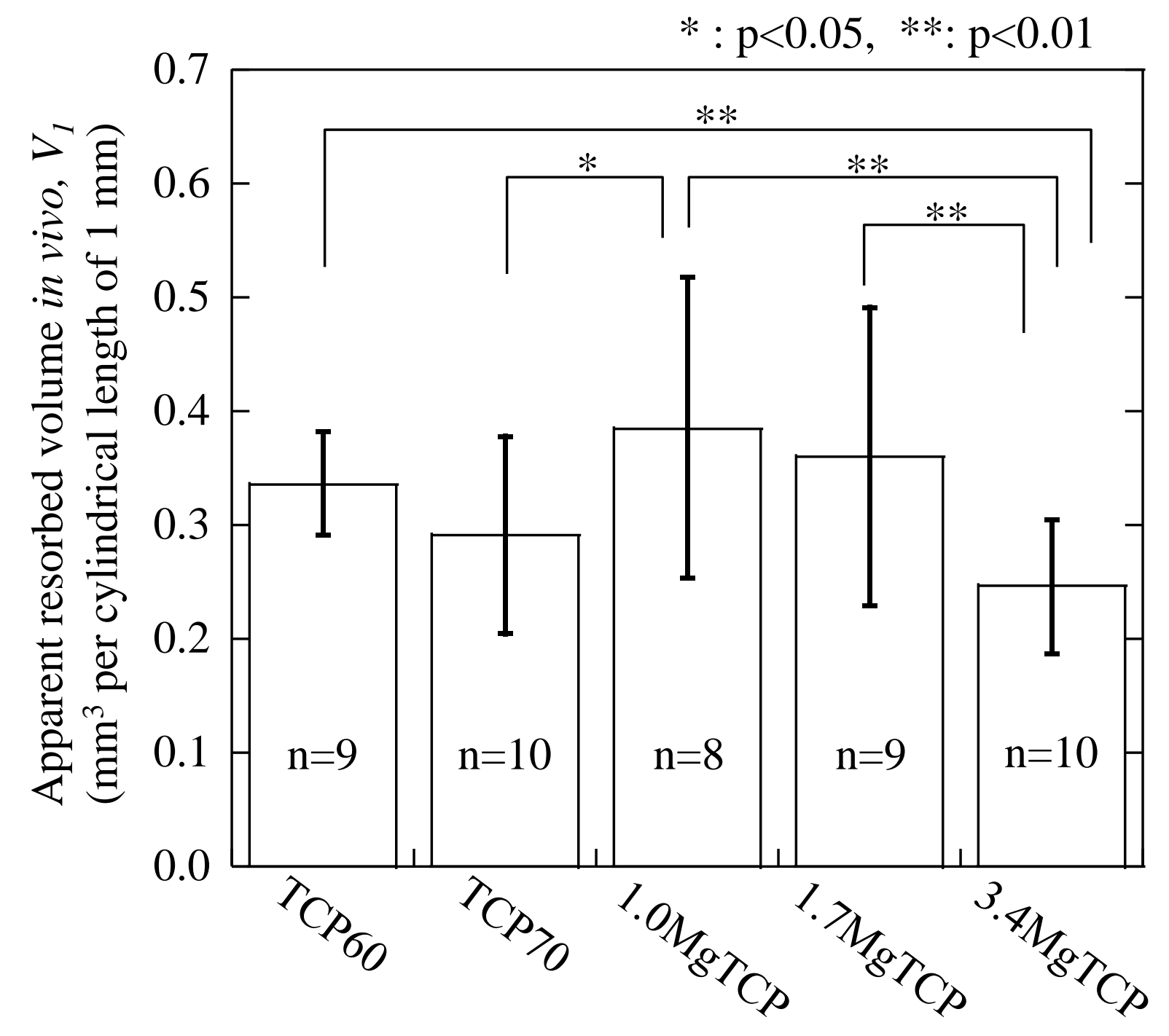

Figure 8 

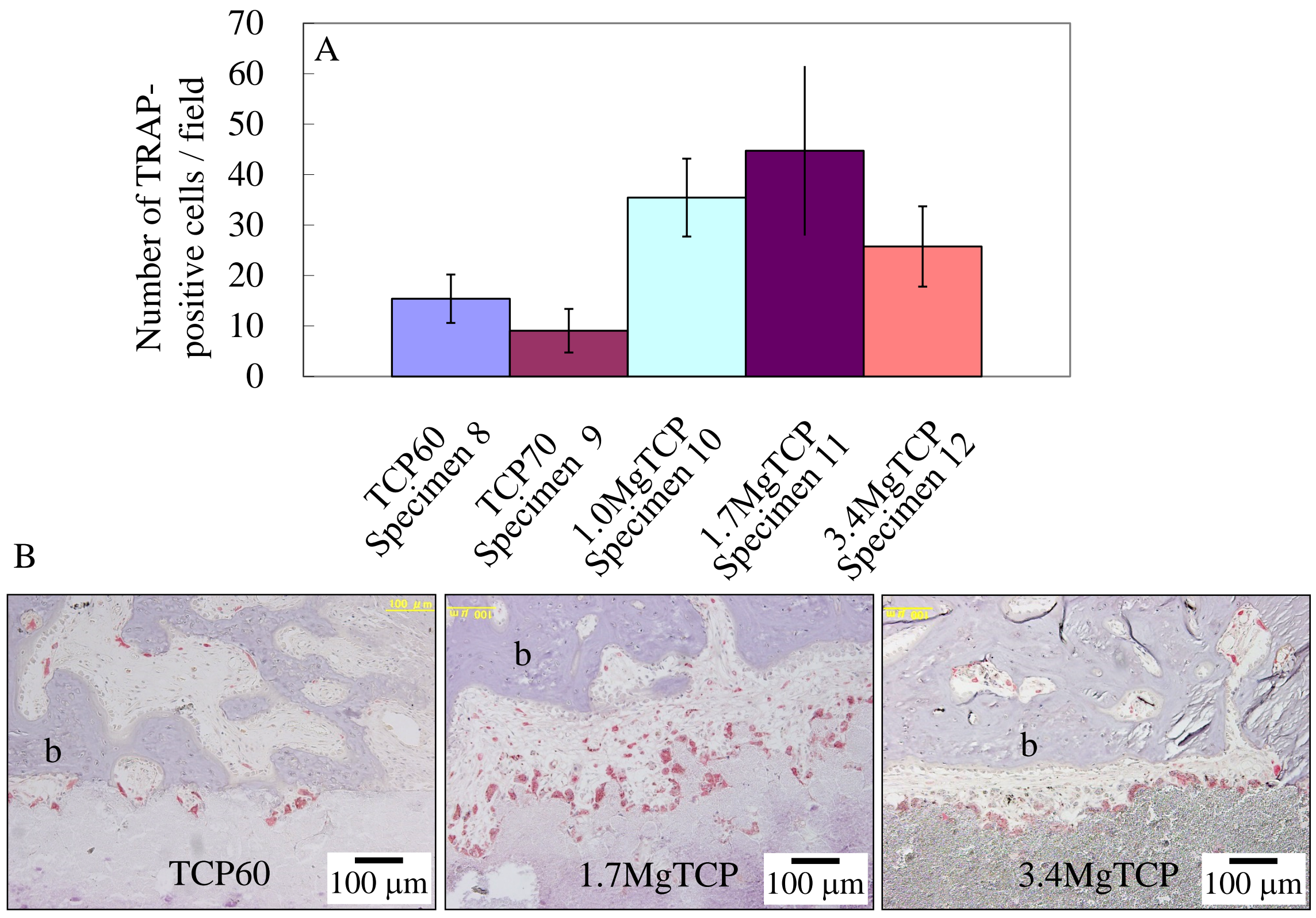

Figure 9 


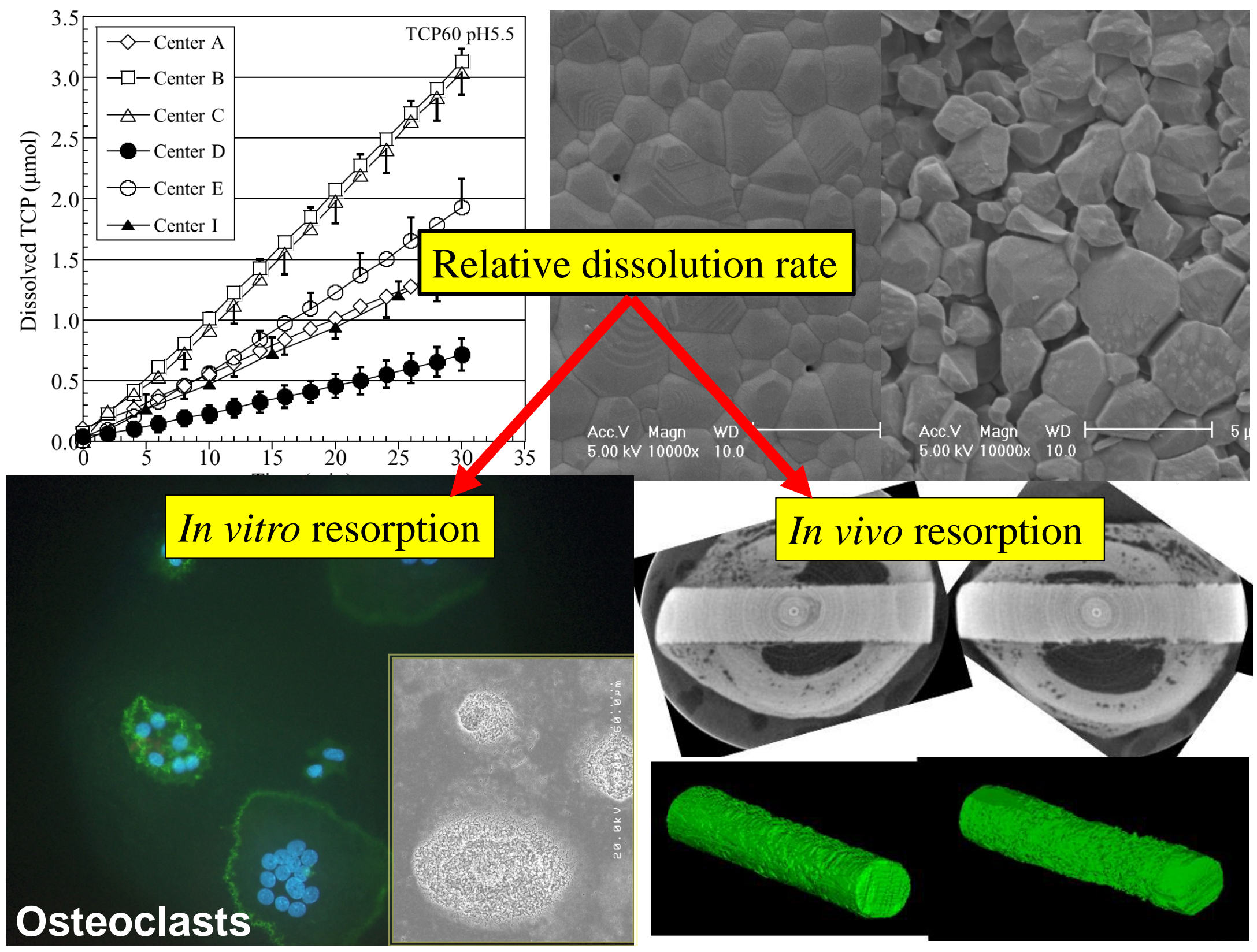

